\title{
Feedback for a simulation practice on communication skills in pharmacy education: A pilot study
}

\author{
Elif Ulutaş Deniz ${ }^{1}$ *, Bilge Sözen Şahne ${ }^{1}$, Selen Yeğenoğlu ${ }^{1}$, Melih Elçin ${ }^{2}$ \\ 1 Department of Pharmacy Management, Faculty of Pharmacy, University of Hacettepe, Ankara, Turkey \\ 2 Department of Medical Education and Informatics, Faculty of Medicine, University of Hacettepe, Ankara, Turkey \\ * Correspondence: eczelifulutas@gmail.com (E.U.D.); Tel. +90 031230542 26; Fax. +90312311 47 77; ORCID No: \\ 0000-0001-7257-9224.
}

Received: 24 October 2017; Revised: 3 January 2018; Accepted: 6 January 2018

\begin{abstract}
Although simulation practice with standard patients became popular in curriculums since years of various countries, it hasn't been used in the education of pharmacists and pharmacy technicians in Turkey yet. In this study, it is aimed to conduct a pilot study with standard patients on students in the simulation laboratory for the first time and get feedback of them. This study was conducted with 22 pharmacy technicians, four pharmacy students and four standard patients in 15-16 December 2015. Six scenarios were used. After the study, video recordings of the "student-standard patient interaction" were watched with the students to improve the simulation laboratory and the practices planned to be. The physical properties of the place, the use of body language, issues related to the needs and feelings during practice for the development of training programs has come to fore during the feedback of the students. It is useful to generalize this pilot study in terms of both student groups for starting their profession with communication skills and achieving the golden standards in education.
\end{abstract}

KEYWORDS: Simulation; pharmacy education; standardized patient; Turkey.

\section{INTRODUCTION}

Communication is very important for the healthcare professionals in the provision of patient oriented healthcare services [1,2]. With the effective use of communication skills, it is possible to prevent problems in the interaction between the healthcare professionals and the patients $[2,3]$. Furthermore, it is necessary for the healthcare professionals to achieve these skills during their undergraduate training. In this context, various techniques such as role-playing, video recordings, movies, real and/or standardized patient encounters can be used in these trainings [4].

On the other hand patient counselling is an important component of patient oriented care process, and pharmacists have significant roles regarding self-treatment, reviewing the medication and pharmaceutical care in this process. Regarding this role of the pharmacists, the pharmacy students should be equipped with a training to acquire communication skills. Trainings in this field will help them improve their critical thinking and clinical decision making skills, and solve motivational and behavioral problems of the patients $[5,6]$. In order to achieve these objectives, simulation based education is preferred in pharmacy programs. Simulation based education is widely used in all health-care related fields to acquire communication, inter-professional and clinical skills $[7,8]$.

\subsection{Simulation techniques}

Simulation is defined by Gaba as "a technique to replace or amplify real experiences with guided experiences that evoke or replicate substantial aspects of the real world in a fully interactive manner" and can be used as part of other learning/teaching methods such as case studies, classroom discussions, project based learning, problem based learning and game based learning $[5,7,9,10]$. Simulation based education is not only used to acquire technical abilities but also to improve and assess communication skills [3, 11].

Various techniques such as role-playing, standardized/simulated patients, video simulations, and high fidelity simulators can be used in simulation based education [12, 13]:

How to cite this article: Ulutaş Deniz E, Sözen Şahne B, Yeğenoğlu S, Elçin M. Feedback For A Simulation Practice on Communication Skills in Pharmacy Education: A Pilot Study. Marmara Pharm J. 2018; 22(2): 314-321. 
Role-playing: It is a group exercise in which two or three students participate in the situation in front of a group of observers after reading the short description of the scenario that they will play. Role-playing is used to give information, attitude and skills to students. It is a technique, which enables the investigation of patient, process, and environment focused skills [14].

Standardized/simulated patients: Standardized patients have been used in teaching communication and clinical skills to healthcare professionals since 1960's. Standardized patients (SPs) are individuals who are trained to portray a patient accurately and consistently [15-17]. These individuals might be community volunteers, actors, faculty staff or administrative personnel [18]. Standardized patients are mostly used to teach process and environment focused skills in relation to quality management, patient oriented skills such as clinical and communication skills, and enable self-assessment and curriculum evaluation [10, 15, 16, 19-23].

Video simulations: This technique is often used to exhibit physical examination techniques, dynamic processes, and teach communication skills, professionalism and ethics [15]. It is indicated that self-assessment is applicable, practical and informative for students in a video based education [24].

High Fidelity Patient Simulators: This technique is used to simulate patient care activities. Patient simulation and feedback might be useful to identify the individual needs of the students and fulfil such needs immediately [25]. In addition to being multidirectional and advanced, patient human simulators include responsive eyes, patient voices, gestures, heart, respiratory and bowel sounds [15].

Standardized patients are frequently used in the educational activities designed for acquiring, improving and assessing communication skills [16]. Such simulation practices are quite effective in determining health problems and treatment of such problems as well as identifying the problems in verbal and non-verbal communication skills with the patient $[2,11]$. Studies have presented various benefits of the simulation practices particularly the impact of feedback on the educational outputs $[4,11,14,15,21-23,26-31]$ :

- Students of a profession provide patient care in a reliable and realistic environment together with other healthcare professionals when necessary through a process of critical decision-making $[9,11,32]$.

- Students have the chance to conduct clinical practices without putting the patients in risk (26).

- Students improve their levels of knowledge, commitment to ethical values, communication skills and selfconfidence $[4,10,26-28]$.

\subsection{Simulation based pharmacy education}

We should provide appropriate instructional methods for pharmacy students so that they can acquire the required competencies for patient oriented care. While teaching a skill, lecturing, demonstration and feedback are important components of the process: students can observe how the educators perform the skill during the demonstration, and they can improve their performances after receiving feedback from the educator. Continuous evaluation of the students and providing instant feedback creates a learning environment, which maximizes the learning levels (i.e. medication and patient consultancy) as well as minimizing the workload (i.e. prescription verification) of the instructors and students. Such an environment can improve the effective skills and abilities required for the students to become authorized and competent pharmacy practitioners [33]. Hence, in many countries, simulation is considered to be an instructional technique in pharmacy training to prepare the students for professional practices $[6,18,23]$.

Simulation based pharmacy education is used in teaching the subject areas like pharmacology practices, medication management, physical evaluation, pharmaceutical care and pharmacotherapy and communication $[12,26]$. Simulation based activities improve the basic knowledge, clinical performance and self-confidence of the student, reduce the medication management mistakes, and encourage the student for critical thinking. Although simulation does not substitute the activities that the students spend with real patients, it offers opportunities to prepare the students, supports the classroom activities, fulfils the curriculum objectives, and standardizes the experiences [34].

There are also studies which reveal that students practice their pharmacy legislation knowledge, investigate the impact of careless behaviors on the job performance, and test their skills on noticing violations during the simulation activities [10].

It is stated that it would be possible to teach how to answer the patients' questions appropriately, collect patient information to fill in prescription, evaluate the patients' concerns, determine the patients who need to talk with pharmacist, respond in an empathic way to patients' concerns, interact with the patients with low levels of literacy, interact in multicultural circumstances, provide information to the patients in a meaningful and remindful way during the simulation based education of both pharmacist and pharmacy technicians [35]. 
Although it has becoming more and more popular in the pharmacy curricula of various countries recently, simulation techniques, especially standardized patients have not been used in the education of pharmacists and pharmacy technicians in Turkey yet. To demonstrate the importance of using this technique in both pharmacist and pharmacy technicians' education programs, and to start such a program, this study was designed on April 2015. To the best of authors' knowledge this is the first study conducted with the pharmacy and pharmacy technician students in a simulation center by using standardized patients, in Turkey.

\section{RESULTS}

All the participants stated that they were satisfied with the practice. The feedbacks received from the participants were grouped under 4 thematic subheadings: Physical conditions of the facility, body language of the participants, participants' educational expectations, and participants' feelings during the activities.

\subsection{Physical conditions of the facility}

Participants who are pharmacy students (PS) and pharmacy technician students (PTS) encountered some challenges during the activities, and expressed their opinions about the facility:

A.1. "Physical organization is quite important to decrease mistakes. The place was small." (PS3)

A.2. "I prefer an actually working computer, and enough place to prepare that medication at the back." (PTS4)

A.3. "Bench should be longer and access to medications by the patients should be prevented." (PS3)

A.4. "The patient was in my circle. I was disturbed. I wish the patients didn't get into our distance." (PTS18)

A.5. "I could not figure out where to sit." (PS3)

A.6. "The banks may be getting closer. Seems to be ready for entry." (PS1)

A.7. "I did not know what to do or where to stop because of the gap between the tables." (PS4)

\subsection{Body language}

The pharmacy and pharmacy technician students provided several comments and opinions on using their body language during their interactions with the patients and caregivers.

B.1. "I have not noticed that I made so many movements. My hands never stopped." (PTS14)

B.2. "I used my hands a lot because of anxiety. I spent so much time looking for the medications." (PTS13)

B.3. "I focused on the table too much." (PTS18)

B.4. "The patient stopped very far, I wanted to get close to him/her" (PS5)

B.5. "They constantly stayed in constant contact with the patient." (PS2)

B.6. "He/she was very relaxed, for example, leaning on his hand." (PTS13)

B.7. "I always played with ... but I do it all the time." (PTS18)

\subsection{Participants' educational expectations}

The participants expressed their satisfaction on the training, their desire to have more similar opportunities, and their expectations for having more training.

C.1. "It would be better if we repeat this practice. Thus, we will make less mistakes." (PS5)

C.2. "We will do our internship in the summer of third year. It would be more meaningful before and after the internship. It would also be better if we do this in the last year or in the fall semester of the fourth year." (PS4)

C.3. "There should be more practice. Each student should do it a few times." (PS5)

C.4. "I think it is good. It is quite useful to see what we can do, what we may encounter. You can do this in the following years within the scope of the course." (PS6)

C.5. "...It would be good for us to have something like education in advance, such as these (scenarios) may come" (PTS4)

C.6. "Similar things are done in some other lessons but only on prescription. We do not do anything about this side of the business." (PS4)

C.7. "(If we do it more), our mistakes are reduced." (PTS4) 


\subsection{Participants' feelings during practice}

The participants experienced such a training program for the first time, and shared their feelings about their experiences.

D.1. "I got excited." (PTS16)

D.2. "I got excited. Normally I wouldn't do that." (PTS17)

D.3. "... I didn't know what to do." (PTS1)

D.4. "I think it was a very impressive practice." (PS3)

D.5 "I was trying to communicate with patients. Both were looking into my eyes at the same time. I was excited by a side. I started to stutter. I could not communicate." (PTS18)

D.6. "Me myself would like to prove it with the ingredients. For example, I would like to allow rest her/him and offer him/her something to drink/eat until pharmacist come." (PTS4)

D.7. "... I was confused what I would do." (PS2)

\section{DISCUSSION}

As one of the most accessible healthcare service providers, pharmacists' communication skills are the most important competencies of them. Effective interpersonal communication is essential in pharmacy routine in order to improve pharmacist-patient interaction, which leads to higher quality services. The report of World Health Organization titled "Preparing the Future Pharmacist: Curricular Development", states that pharmacist should be informed and confident in communication with other healthcare professionals and the society as a communicator, and communication skills should include verbal, non-verbal, listening, and writing skills [36]. Hence, pharmacy students should acquire the competence to cooperate and communicate with the patients and other healthcare professionals.

According to the National Pharmacy Core Curriculum developed in 2015, acquiring competency in a social field such as communication, which is one of the essential qualities of a professional, is important in terms of completely exhibiting the ethical and human values required by healthcare services, and such professionals should be provided with adequate training during the education process [37]. Accreditation Council for Pharmacy Education (ACPE) states that communication skills such as interview techniques; active listening, empathy, and problem solving should be emphasized in pharmacy curricula [31].

Regarding the fact that simulation is one of the effective methods, which can be used to provide communication skills to pharmacy students, Council has approved the use of simulation for up to $20 \%$ of the 300-hour experimental education in Introductory Pharmacy Practice Experience (IPPE) courses [34]. In various studies, the conclusions are especially focusing on the standardized patients as the preferred modality of the simulation for communication skills $[6,8,9,13,36,38]$.

In this study, the pharmacy and pharmacy technician students were satisfied with the standardized patient methodology. They provided written feedback with a focus on the importance of body language, which was considered as a significant component of interpersonal communication, and they suggested that the use of body language should be covered more in the undergraduate communication courses. Parallel to this, body language is more prominent especially in multicultural communities [39].

On the other hand, simulation enables students to identify the incomplete information they have, and analyze their learning needs [2]. In present study, the students mentioned the importance of simulation activities to support their achievement in professional practices. They emphasized the importance of deliberate practice; they could learn better when they participated in the situations, made mistakes and got feedback. Gallimore et al. stated, $89 \%$ of the students in their study expressed that simulated patients prepared them for meeting the real patients [40]. In another study, it was stated that $96.5 \%$ of the students who participated in a simulation based program for communication training found this practice useful, too [14]. Most of the students in a 2015 study, mentioned that the feedback they received from the standardized patients helped them to determine their strengths and weaknesses in patient consultancy [10]. Another study by Rickles et al. presented that $89.1 \%$ of the pharmacy students found the simulation practice with standardized patients was useful [31]. Furthermore over $90 \%$ of the students expressed that simulation improved the level of comprehending their professional roles in a study conducted in 2012 [30]. Also, in a study conducted in 2014, it was revealed that patient human simulation was more effective than case based learning in terms of improving, the understanding and comprehending levels of the students [23]. Recently, participants of a study reported that simulation applications improved their self-confidence and professional skills [41]. 
In addition, these physical conditions of the simulated pharmacy should provide appropriate environment for patient-pharmacist/pharmacy technician interactions [42, 43]. In this study, the pharmacy and pharmacy technician students expressed their dissatisfaction with the facility; especially the computer, shelves and the narrowness of the place. Following their suggestions, 'Simulated Pharmacy' was reorganized, and an operational computer was provided for the students in their following practices (Figure 3).

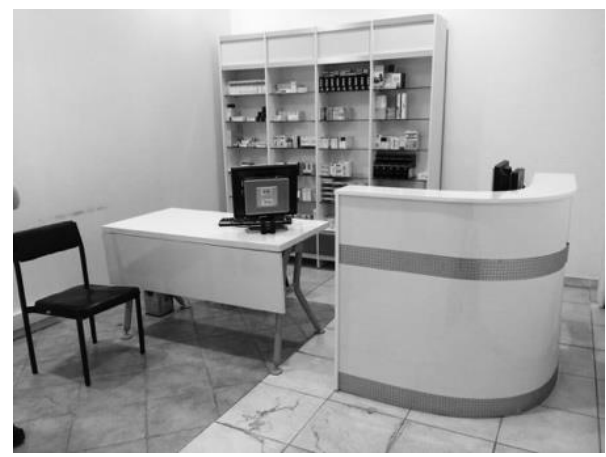

Figure 1

\section{CONCLUSION}

As a result it can be stated that in the process of improving the pharmacy education in Turkey, implementation of simulation-based educations for communication skills is quite significant. The students will have the opportunity to begin their profession with these skills, and the institutions will get the chance to achieve the golden standards in education. It is for sure that this pilot study will be a model for other pharmacy faculties that are about to start the studies for implementing simulation practices in their curricula. It is observed that specified simulated pharmacy provided an appropriate environment for teaching communication skills to both of student group in an effective and efficient way. In the light of the all obtained findings, it can be stated that the pharmacy service quality will be improved with the advancements in related subjects, especially by effective patient-pharmacist and pharmacy technician communication.

\section{MATERIALS AND METHODS}

\subsection{The Facility}

There is a 'simulated pharmacy' in the Interprofessional Education and Simulation Center at Hacettepe University. The pharmacy has one table, two chairs, one bench, two cameras in front and at the back of the bench and various medications on the shelves behind the bench (Figure 1,2).

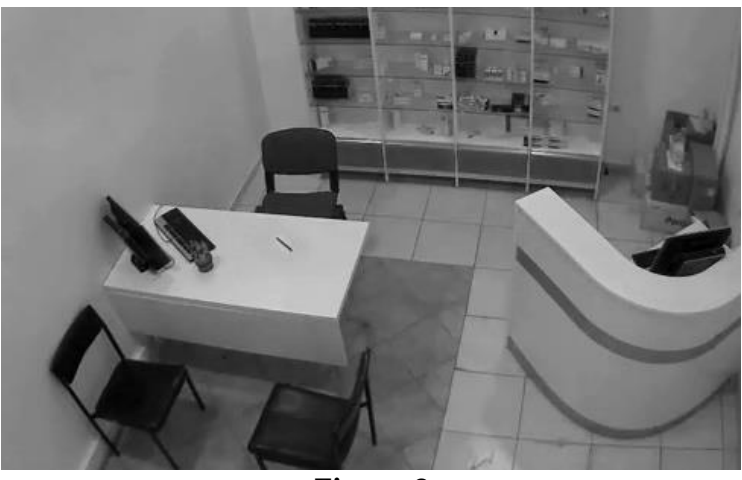

Figure 2

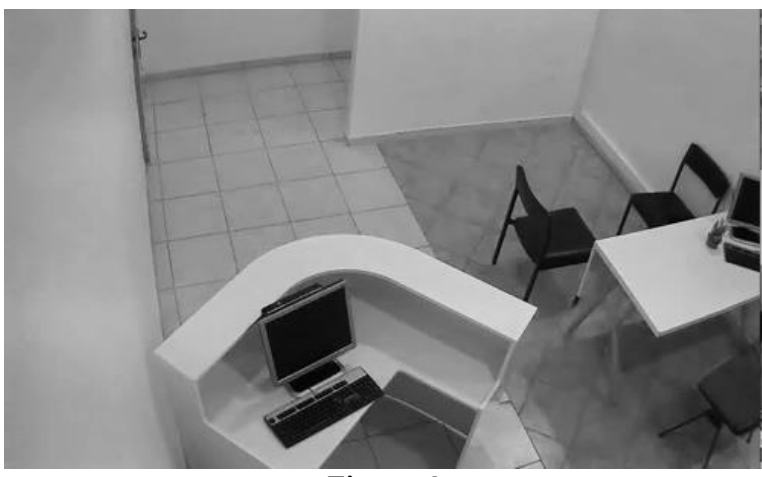

Figure 3

\subsection{The participants}

The participants of the study were third year pharmacy students who enrolled the course, Community Pharmacy Management and second year pharmacy technician students who enrolled the course, Pharmacy Services Management at Hacettepe University. The aim and methodology of the study were explained to them, and they were invited to be the participants of the study. 22 pharmacy technician students $(96 \%)$ and 4 pharmacy students (13\%) volunteered to participate in the study, 16 - 17 December 2015. 


\subsection{The educational process}

Six scenarios were developed with different educational aims (Table 1). In this context, four standardized patients were trained each portraying different patients and caregivers in nine scenarios by the authors. Twenty-two pharmacy technician students and one pharmacy student participated in the scenarios 1-6. Three pharmacy students participated in the scenarios 4-6. The scenarios were randomly assigned to the students.

Table 1. Scenario name and aims.

\begin{tabular}{|c|l|l|}
\hline Scenario No & Scenario Name & Scenario Aim \\
\hline $\mathbf{1}$ & Antibiotic use & To offer drug in a proper way and compliance with the legislation \\
\hline $\mathbf{2}$ & Drug abuse & To be aware of abuses \\
\hline $\mathbf{3}$ & $\begin{array}{l}\text { Preparation of } \\
\text { magisterial drug }\end{array}$ & To manage the situation without a pharmacist \\
\hline $\mathbf{4}$ & Tobacco use I & To demonstrate the ability to convince a patient about tobacco use \\
\hline $\mathbf{5}$ & Tobacco use II & To draw attention to the patient about tobacco use \\
\hline $\mathbf{6}$ & Patient privacy & To be aware of patient privacy \\
\hline
\end{tabular}

Each student was asked to interview with the patient or caregiver for approximately 5 minutes. All performances were recorded with two cameras and one voice recorder. The recordings were watched and feedback were provided by the students and the researchers in the debriefing session.

At the end of the debriefing session, students were asked to provide written feedback about the educational activity. The feedback forms were evaluated by the researchers, and the content was grouped under thematic subheadings.

Author contributions: Concept -S.Y., B.S.Ş., E.U.D.; Design - S.Y., B.S.Ş., E.U.D.; Supervision - S.Y., M.E., B.S.Ş., E.U.D.; Resource - B.S.Ş., E.U.D.; Materials - B.S.Ş., E.U.D., M.E.; Data Collection and/or Processing - B.S.Ş., E.U.D., M.E.; Analysis and/or Interpretation - B.S.Ş., E.U.D., M.E.; Literature Search - B.S.Ş., E.U.D.; Writing - S.Y., M.E., B.S.Ş., E.U.D.; Critical Reviews - S.Y., M.E., B.S.Ş., E.U.D.

Conflict of interest statement: The authors declared no conflict of interest.

\section{REFERENCES}

[1] Horton N, Payne KD, Jernigan M, Frost J, Wise S, Klein M, Epps J, Anderson HG. A standardized patient counselling rubric for a pharmaceutical care and communications course. Am J Pharm Educ. 2013;77(7):152.

[2] Galato D, Alano GM, Trauthman SC, França TF. Pharmacy practice simulations: performance of senior pharmacy students at a University in southern Brazil. Pharm Pract.2011;9(3):136-140.

[3] Fejzic J, Barker M. Implementing simulated learning modules to improve students' pharmacy practice skills and professionalism. Pharm Pract. 2015;13(3):1-8.

[4] Turan S, Elçin M, Uner S, Odabaş1 O, Sayek I, Senemoglu N. The impact of clinical visits on communication skills training. Patient Educ Couns. 2009;77(1):42-47.

[5] Mesquita AR, Souza WM, Boaventura TC, Barros IM, Antoniolli AR, Silva WB, Junior DPL. The effect of active learning methodologies on the teaching of pharmaceutical care in a Brazilian Pharmacy Faculty. PloS One 2015:10(5); e0123141.

[6] Chiau TP, Ali AM, Bakry MM, Azmi N, Paraidathatu T. Video recording feedback in communication and counselling among pharmacy students. Is it better than verbal feedback? Indian J Pharm Educ Res. 2016;50(2):246-250.

[7] Gaba DM. The future vision of simulation in health care. Qual Saf Health Care. 2004;13(Suppl 1):i2-i10.

[8] Vyas D, Bray BS, Wilson MN. Use of simulation-based teaching methodologies in US colleges and schools of pharmacy. Am J Pharm Educ. 2013;77(3):53.

[9] Ray SM, Wylie DR, Shaun Rowe A, Heidel E, Franks AS. Pharmacy student knowledge retention after completing either a simulated or written patient case. Am J Pharm Educ. 2012;76(5):86.

[10] Stewart R, Baggarly S, Chelette C. Student self-assessment of knowledge and application of legal concepts in a community pharmacy simulation. Curr Pharm Teach Learn. 2013;5(6):499-507.

[11] Crea KA. Practice skill development through the use of human patient simulation. Am J Pharm Educ. 2011;75(9):188. 
[12] Kane-Gill SL, Smithburger PL. Transitioning knowledge gained from simulation to pharmacy practice. Am J Pharm Educ. 2011:75(10);21.

[13] Beaubien J, Baker D. The use of simulation for training teamwork skills in health care: how low can you go? Qual Saf Health Care. 2004:13(suppl 1):i51-i56.

[14] Nestel D, Tierney T. Role-play for medical students learning about communication: Guidelines for maximising benefits. BMC Med Educ. 2007;7(1):1.

[15] Lane JL, Slavin S, Ziv A. Simulation in medical education: A review. Simul Gaming 2001:32(3):297-314.

[16] Lin K, Travlos DV, Wadelin JW, Vlasses PH. Simulation and introductory pharmacy practice experiences. Am J Pharm Educ. 2011;75(10):209.

[17] Mesquita AR, de Oliveira Sá DAB, Santos APAL, de Almeida Neto A, Lyra Jr DP. Assessment of pharmacist's recommendation of non-prescription medicines in Brazil: a simulated patient study Int J Clin Pharm. 2013;35(4):647655.

[18] Smithson J, Bellingan M, Glass B, Mills J. Standardized patients in pharmacy education: An integrative literature review. Curr Pharm Teach Learn. 2015:7:851-863.

[19] May W, Park JH, Lee JP. A ten-year review of the literature on the use of standardized patients in teaching and learning: 1996-2005. Med Teach. 2009;31(6):487-492.

[20] Robinson JD, Bray BS, Willson MN, Weeks DL. Using human patient simulation to prepare student pharmacists to manage medical emergencies in an ambulatory setting. Am J Pharm Educ. 2011;75(1):3.

[21] Haddad A. What health science students learn from playing a standardized patient in an ethics course. Camb Q Health Ethics. 2010;19(04):481-487.

[22] Elçin M, Odabaşı O, Turan S, Sincan M, Başusta NB. Tıp eğitiminde iletişim becerilerinin standart hastalar ve yapılandırılmış değerlendirmelerle geliştirilmesi. Acta Medica 2010;41(4):219-230.

[23] Chin KL, Yap YL, Lee WL, Soh YC. Comparing effectiveness of high-fidelity human patient simulation vs case-based learning in pharmacy education. Am J Pharm Educ. 2014;78(8):Article 153.

[24] Zick A, Granieri M, Makoul G. First-year medical students' assessment of their own communication skills: a videobased, open-ended approach. Patient Educ Couns. 2007;68(2):161-166.

[25] Seybert AL, Kane-Gill SL. Elective course in acute care using online learning and patient simulation. Am J Pharm Educ. 2011;75(3): 54 .

[26] Eukel HN, Frenzel JE, Skoy ET, Focken RL, Fitz AL. An introductory pharmacy practice experience using simulated patient care activities in a pharmaceutical care laboratory environment. Curr Pharm Teach Learn. 2014;5:682-691.

[27] Rickles NM, Tieu P, Myers L, Galal S, Chung V. The impact of a standardized patient program on student learning of communication skills. Am J Pharm Educ. 2009;73(1):1.

[28] Turan S, Üner S, Elçin M Standart Hasta Geribildiriminin Öğrencilerin Güdülenme Düzeyine Etkisi. Balkan Med J. 2010;28:43-48.

[29] Martin D, Regehr G, Hodges B, McNaughton N. Using videotaped benchmarks to improve the self-assessment ability of family practice residents. Acad Med. 1998;73(11):1201-1206.

[30] Vyas D, McCulloh R, Dyer C, Gregory G, Higbee D. An interprofessional course using human patient simulation to teach patient safety and teamwork skills Am J Pharm Educ. 2012;76(4):71.

[31] Chen Y-C, Kiersma ME, Abdelmageed A. Evaluation of student perceptions of standardized patient simulation on patient counseling confidence during introductory pharmacy practice experiences. Curr Pharm Teach Learn. 2015;7(6):811-818.

[32] Vyas D, Bhutada NS, Feng X. Patient simulation to demonstrate students' competency in core domain abilities prior to beginning advanced pharmacy practice experiences. Am J Pharm Educ. 2012;76(9):176.

[33] Qi Y. Repeated testing to improve skills in a pharmacy practice laboratory course. Am J Pharm Educ. 2013;77(6):130.

[34] Seybert AL. Patient simulation in pharmacy education. Am J Pharm Educ. 2011;75(9):187.

[35] Wilson DL, Kimberlin CL, Brushwood DB. Exploring the professional expertise of pharmacy technicians. J Pharm Technol. 2005;21(6):341-347.

[36] Wallman A, Vaudan C, Sporrong SK. Communications training in pharmacy education, 1995-2010. Am J Pharm Educ. 2013;77(2):36. 
[37] Mezuniyet Öncesi Eczacılık Eğitimi/ Ulusal Çekirdek Eğitim Programı, Eczacılık Egĭtiminde Temel Ve Sosyal Bilimlerin Yeri. 205; Ankara/Turkey. http://euk.saglik.gov.tr/eczcep2015/index.html

[38] Bray BS, Schwartz CR, Odegard PS, Hammer DP, Seybert AL. Assessment of human patient simulation-based learning. Am J Pharm Educ. 2011;75(10):208.

[39] Sales I, Jonkman L, Connor S, Hall D. A comparison of educational interventions to enhance cultural competency in pharmacy students. Am J Pharm Educ. 2013;77(4): 76.

[40] Gallimore C, George AK, Brown MC. Pharmacy students' preferences for various types of simulated patients. Am J Pharm Educ. 2008;72(1):4.

[41] Fejzic J, Barker M, Hills R, Priddle A. Communication Capacity Building through Pharmacy Practice Simulation. Am J Pharm Educ. 2016;80(2):28.

[42] MacLeod-Glover N. Communication Pharmacy Practice: An Overview, Communications Centre National Continuing Education Program. 2006;1-8.

[43] Ulutaş E, Sözen Şahne B, Yeğenoğlu S. Eczacılıkta iletişimin rolü. Marmara Pharm J. 2015;19:200-207.

This is an open access article which is publicly available on our journal's website under Institutional Repository at http://dspace.marmara.edu.tr. 